\title{
ACCOUNTABILITY AND REFLECTIVE RESPONSIBILITY IN INFORMATION SYSTEMS
}

\author{
Bernd Carsten Stahl \\ Centre for Computing and Social Responsibility, Faculty of Computer Science and \\ Engineering, De Montfort University, The Gateway, Leicester LE1 9BH, UK \\ bstahl@dmu.ac.uk
}

Abstract: This paper discusses the role of accountability in responsibility ascriptions regarding information and communication technology (ICT). It starts with a definition of responsibility as the social construct representing the ascription of an object to a subject. Recounting the traditional responsibility, the paper will point out the weaknesses of responsibility with regards to ICT. It will then propose an alternative way of dealing with responsibility under the heading of "reflective responsibility". Accountability will be defined as the structures and institutions that establish a link between object and subject. As such it is a necessary condition of successful responsibility ascriptions. The paper will discuss the influence of ICT on the construction of accountability and consequently on responsibility. It will highlight the problem of pathological accountability where accountability becomes reified and solidified and in effect goes counter to the social aim of responsibility. The paper will conclude with a discussion of how problems and pathologies of accountability can be overcome in order for reflective responsibility to be able to fulfil its purpose.

Key words: Responsibility, accountability, ICT, pathological accountability, reflective responsibility 


\section{INTRODUCTION}

What is the meaning of the metaphor of "landscapes of ICT and social accountability"? It would seem to imply several things. First, there is the assumption that ICT and accountability are related in some way and that this accountability is of a social nature. Furthermore, it implies that there is no unambiguous picture of the relationship of accountability and ICT. Instead, the metaphor of the landscape suggests that there are different types of relationships and that there are different approaches to these landscapes just as there are different types of landscapes (hills, mountains, deserts, ...) and one can approach them differently (walk, fly, drive, ride,...). When walking through such different landscapes it is important to know where one is and wants to go in order to ascertain that one has the right equipment and the right companions.

This paper will explore the overlap of a number of different landscapes. On one hand, it is based on the debate within the field of computer and information ethics. It is informed by what the philosophical interest in information and communication technology has to say about possible approaches to ethical issues. On the other hand, it is interested in the organisational use of ICT and thus in the subject area of the discipline of information systems (IS).

\section{RESPONSIBILITY AND ICT}

Accountability describes the structures that need to be in place to facilitate responsibility. In order for this concept to be convincing, we need to make it clear what is meant by responsibility. Since the concept of responsibility presented here will no doubt be somewhat different from what most readers may understand by that term, a brief literature review will be provided on the concept of responsibility. This will lead to a discussion of the traditional understanding of responsibility and the answer to these problems, namely reflective responsibility. In this short conference paper, it will not be possible to do justice to all of the niceties of the debate on responsibility. The interested reader can find a more comprehensive discussion of the topic in Stahl (2004).

\subsection{Definition of Responsibility}

"Responsibility" is a term with many meanings. Very briefly, responsibility can best be defined as the ascription of an object to a subject. 
The subject is the entity, usually a person, who is responsible. The object is that which the subject is responsible for. A responsibility ascription thus renders the subject answerable for the object. The ascription that is the heart of responsibility is a social process. It socially constructs realities out of the perceptions of the agents involved (Hart, 1948). In order to understand such an ascription, it is important to take into account its underlying motivation. There are a number of possible aims that can be intended through the ascription of responsibility. These include retribution (Fauconnet, 1997) and revenge (Nietzsche, 1987) but are usually of a more positive nature.

Responsibility ascriptions generally aim to improve the individual and social existence of the individuals who are involved. They do so by determining whether consequences of an action are desirable and accordingly deciding on sanctions for certain actions. This means that the attribution of sanctions, be they positive or negative, are of central importance for responsibility (Bayertz, 1995). Responsibility aims to affect social change for the benefit of those involved in the ascription. It is important to keep this fundamental tenet of responsibility in mind because it can explain some of the dimensions of responsibility and it will also allow us to identify instances where accountability becomes counterproductive to responsibility.

A complete ascription of responsibility involves a number of other aspects and dimensions in addition to the subject and the object. Chief among them are the authority and normative basis. In order for responsibility to be ascribed, there must be a normative rule to which the ascription can refer. In some cases such rules are relatively easy to determine, such as the law in legal responsibility. In other cases they may be less simple to find, for example in the case of moral responsibility. However, a responsibility ascription that is to be successful in improving social reality must be based on acceptable rules that the individuals involved are ready to adhere to. The existence of rules is not enough, since they need to be applied and interpreted in specific situations. This is where the authority finds its place. A responsibility ascription needs to define a relationship between an object and a subject and it needs to do so by imputing sanctions to the subject depending on the object. Such a theoretical definition must be translated into reality and it must be executed, which is the job of the authority. In legal responsibility the authority is the judge or the jury but in other types of responsibility it is often less clear who or what constitutes the authority.

Apart from these main aspects of responsibility, every real ascription must consider a number of other issues. These include the type of 
responsibility (legal, moral, role, ...) the temporal dimension (prospective or retrospective), the type of ascription (transitive, reflexive, vicarious, ...) as well as limits and exemptions. It should be clear that all ascriptions are unique combinations of these aspects that require careful negotiation and implementation. In order to demonstrate the role of accountability in this concept of responsibility, some of the problems of responsibility ascriptions will next be described, and will be used to develop a theory of reflective responsibility.

Finally, the above definition of responsibility may seem a bit dry and the reader may wonder what the relevance to ICT is. The argument will therefore be supported through the use of a hypothetical case: Let us imagine a large multinational organization that decides to introduce an Enterprise Resource Planning (ERP) software. The purpose of the installation of this system is to streamline operations and to provide all the data to important decision makers in real time. At the same time, it can be linked to other organizational systems, such as a Customer Relationship Management (CRM) system and the combined data can be used for strategic purposes such as data mining.

The case should look sufficiently familiar to anybody who has done research in information systems recently. ERP systems were the latest fashion for a while (they may by now have been overtaken by even larger systems such as Supply Chain Management (SCM) or others). The case is thus realistic. At the same time, there is enough literature that is highly critical of ERP systems because they often do not deliver what managers hope they will. They also tend to raise a number of moral issues. The case should not be misunderstood as "proving" anything; rather, it is meant to provide a plausible context for some of the issues of responsibility and accountability in information systems.

\subsection{Problems of Responsibility and ICT}

Problems of responsibility ascriptions can arise with regard to all three of the main dimensions; the subject, the object, and the authority. Responsibility becomes problematic where it cannot fulfill its social role, where it cannot have the desired effects. This is the case where either the relationship between subject and object cannot be established or where the establishment of the relationship does not have any tangible results.

Problems of the subject are those that preclude a possible subject from being successfully seen as responsible and thus being ascribed the object. 
The majority of such problems of the subject are related to a lack of fulfillment of the conditions of responsibility, which will be introduced. The literature on responsibility names a number of conditions, the most important will therefore be supported of which are causality, freedom, power, knowledge, and personal qualities. Causality means that there must be some sort of causal relationship between subject and object. This relationship may be indirect in that the subject did not cause the object but could have had the opportunity to avoid it. A subject may thus be responsible for someone's death because the subject caused it directly, but there could also be an ascription if the subject could have saved the person in question but failed to do so. Causality in our example might be given when the CEO of the company decides to implement the ERP, which means that she is a crucial part of the causal chain that leads to the object. However, it could also be an external expert who knows the situation but fails to inform the CEO of the possible downside and thus gives up the chance to affect the development.

Another typical condition of responsibility is freedom of the subject. The subject not only has to play a causal role in the outcome but he or she must also be in a position to change this outcome. It is usually seen as problematic to ascribe responsibility to subjects who did not possess the freedom to affect the object. This is linked closely to the next condition, namely knowledge. The freedom to affect the outcome of the causal chain resulting in the object requires that the subject be aware of the subject and his or her own role in the development of matters. Without knowledge, there can be no intentional action. The same can be said about power. It is no use for the subject to be causally involved as well as sufficiently free and aware of the situation if it is outside of the subject's power to affect the object. Finally, one can find a number of authors who discuss the importance of personal characteristics for the ascription of responsibility. These personal characteristics include emotions, intentionality and rationality, the ability to act a number of traits that render us sociable such as education and formation, self-control and a bodily existence. These latter personal requirements are important for the subject to react appropriately to the ascription of responsibility. In order for responsibility to be successful, the subject must want to react to the threat of punishment or promise of reward. If this is not given, causality, freedom, power, and knowledge have no purpose.

The philosophically versed reader will have noticed that the conditions of responsibility are deeply problematic and touch on some of the most contentious issues that philosophy has been grappling with for the last few millennia. Since Hume, philosophers have recognized that causality is not a 
natural occurrence, that it is nothing that can ever be observed. We can only observe before and after states but the causal link always remains obscure. A similar, possibly worse concept is that of freedom. In the physical description of the world there is no place for freedom. Natural occurrences follow natural and scientifically recognizable laws. Every state of nature is a necessary consequence of prior states. Since we as humans are part of the natural world, this description applies to us as well. As a result we seem to be completely determined. If, consequentially, there is no freedom, then it is questionable whether responsibility ascriptions can fulfill any purpose (cf. Wallace 1996). Other fundamental problems of these conditions are that we can never know the internal states of persons. That means we cannot know whether they are aware of things and whether they intend certain consequences.

For the purposes of this paper, we will ignore the fundamental philosophical problems. It will suffice to work with the everyday and common sense notions of causality and freedom. We can assume that causal relationships can in many cases be reliably established and that agents have the freedom to act, albeit often within constraints. We can also assume that most of the persons involved in responsibility ascription for the use of ICT are adult and reasonably rational. And yet, even when accepting these ideas, the subject of responsibility for ICT remains problematic.

To demonstrate the point, let us return to the example: the prime exponent of responsibility in organizations tends to be the formal head of the organization, usually the CEO. We could thus say that the CEO is responsible for everything that happens in the company, including the introduction of the ERP. The CEO is well placed to make decisions but she usually lacks the necessary knowledge. She may take the decision to implement the system but she will not normally be able to assess the results in any detail. On the other end of the organizational spectrum, there will be data workers who input and use the system, who may have a better understanding of specific parts of the system but they will usually lack an overview as well as the power to affect things.

It is thus problematic to find subjects who can be ascribed responsibility. However, the subject is not the only dimension producing problems. The object, the thing or fact that the subject is responsible for, can also be problematic. Three problems are cumulative effects, side effects, and the question of doing and omitting. In traditional responsibility ascription the person as the subject is ascribed the clearly identifiable consequences of an intentional act. In many cases the morally problematic aspect of ICT is not 
related to a single intentional act but to the accumulation of a large number of acts. Where the single act is fundamentally unproblematic, the accumulation represents a problem. A nice example of this is the use of a car. While a single use of a car by an individual is typically of no moral interest, the accumulation of uses of cars has a huge range of consequences including many thousands of people killed every year but also a change in social and technical infrastructure that favours the well-off. It is not clear how responsibility for the cumulative effect can be broken down to individual responsibility. A related problem is that of side effects. Responsibility aims to affect intentional acts. However, most, if not all, acts have other effects than those that are intended. How can we ascribe responsibility for these?

A final problem of the object is that of doing and omitting. Traditionally, responsibility is ascribed for acts, not for omissions. I have, however, already mentioned the case of a subject letting someone die despite a chance to intervene. This is a good example of responsibility for omissions. The practical problem this raises is that the inclusion of omissions into the objects of responsibility leads to an infinity of ascriptions. Coupled with the potential infinity of causality, this means that a subject at any time is responsible for an infinite number of consequences, independent of whether the subject acts or not. This is clearly not manageable and will lead to the end of responsibility.

A final problem of responsibility worth mentioning is that of the authority. I have said earlier that the authority is the entity that can determine and enforce the sanctions associated with the responsibility ascription. For this purpose it needs to be based and rely upon a generally accepted normative framework. In the case of moral responsibility, both are hard to come by. There is no generally accepted morality, there is no universal ethical theory and there is no person and no institution that can be relied upon to attribute sanctions and to enforce them.

These general problems can also be detected in our ERP case. A problem of cumulative effect may be that of customer data protection. Noting down the preferences of a customer on a piece of paper is something that merchants have always done in order to please their customers. When the ERP system is supplemented with a customer relationship management (CRM) system, this practice can easily lead to the accumulation of large amounts of information on individual customers. This, in turn, can lead to legal as well as ethical questions. 
Similarly, unintended consequences of systems introduction are frequent. The intention of the ERP system is presumably to increase efficiency, control, and agility. It is easily imaginable, though, that the system will have other consequences. The organization may have to be restructured and some employees made redundant because of this. Some may find their jobs enriched, others impoverished. These are consequences nobody intended, even thought they may have foreseen them. Can we hold the CEO responsible? And to which consequences will this lead? Finally, which are the moral rules that the organization agrees on and who can hold subjects responsible?

\subsection{Reflective Responsibility for ICT}

Because of these problems that preclude a straightforward application of responsibility to many of the problems of ICT, the present author has elsewhere (Stahl, 2004) suggested a concept of reflective responsibility. The idea of reflective responsibility is to determine the core of the concept and to apply this reflexively to itself. Or, to put it differently, it is the question whether a responsibility ascription is indeed an expression of responsibility. In order to do this, it is important to identify the core of responsibility ascriptions. There are three characteristics that most ascriptions share: openness, an affinity to action, and a teleological basis.

Openness stands for the fact that responsibility ascriptions are not closed and not predictable but, as social constructs, they are open to change. That means that it is not possible to exclude stakeholders from the ascription process and that the outcome of the ascription is always in some doubt. This is true for the most formalized of responsibility ascriptions, legal responsibility, where external stakeholders may appear as experts or witnesses in a court of law. Also, it is impossible to predict the outcome of a case even though one may in many cases guess what it will be. For less formalized types of responsibility such as moral responsibility, the aspect of openness is even stronger.

The second characteristic of reflective responsibility is the affinity to action. This stands for the fact that responsibility ascriptions always carry the promise that they will lead to a manifest change of some description. Holding someone responsible means that that person will change their ways and that social reality will be affected as a result. This is closely linked with the purpose of responsibility, namely to make life better for those involved. 
The final characteristic is that of teleology. This teleological orientation has two aspects: consequentialism and the "good life". The good life represents the above mentioned property of responsibility to improve social reality. Such an improvement is only possible if there is a vision as to what a desirable society or social life would look like. Responsibility ascriptions therefore aim, explicitly or implicitly, to achieve some sort of social result. Furthermore, responsibility ascriptions are based on consequences rather than intentions. In many cases these consequences may not (yet) be known but the consequentialist direction is something that seems to the general rule for responsibility ascriptions.

Reflective responsibility takes these three characteristics, (openness, affinity to action, and teleology), and applies them to responsibility ascriptions. It asks whether an ascription is open, whether it is likely to lead to action and manifest changes and whether it is based on a tenable vision of the good life and considers relevant consequences. There are several ways such reflective responsibility can be realized. What they have in common is that they must be reflective about their nature as social constructs and therefore actively consider the process of construction. This, in turn, coupled with the ethical necessity to recognize the equal dignity of all human beings, means that responsibility ascriptions should be participative endeavours that aim to allow all those who are affected to voice their opinions. Reflective responsibility will therefore in practice look somewhat like a Habermasian (1981) discourse and the present author has argued elsewhere that the Habermasian ideal speech situation is part of what renders such participative responsibility ascriptions ethically legitimate.

To return to our example of the introduction of an ERP system, reflective responsibility would look quite different from the type of responsibility that we usually encounter in commercial organizations. Instead of trying to link given subjects to given or presumed objects and imposing sanctions according to the instrumental rationality of the organization, reflective responsibility would start prior to these steps. In order to be successful it would have to identify the stakeholders. In practice this would mean that someone with a sufficient interest and organizational power, i.e., the CIO, a project manager, or maybe the CEO would have to start the process. During the stakeholder deliberations, all aspects of the ascription would have to be debated. That means that during the process of ascription the subject, object, rules, and authority would have to be identified, and in some cases even constructed. This means that most of the problems of traditional responsibility enumerated earlier can be overcome. Responsibility will be ascribed for those objects that the subjects are in control of and the sanctions 
will be measured in such a way as to facilitate the attainment of the shared goal. Therefore, it is possible that subjects are defined for specific purposes. These would include subjects that are problematic from a traditional responsibility point of view such as collective bodies (Stahl, 2004b) or information processing machines (Stahl. 2004c). Similarly, the process of ascription would comprise the definition and delimitation of the object. This would be done in conjunction with the definition of the subject as well as the norms and sanctions. Problems of cumulative or side effects can thus be addressed as well as the question whether doing and omitting need to be treated differently. Unintended effects of the ERP system could thus be incorporated into the responsibility ascription as long as at least one of the stakeholders raises the prospect. It should be relatively easy to see that the result of such reflective responsibility will not be a single responsibility ascription but a web of interrelated and interdependent responsibilities. This web can easily become quite complex and thereby add to the problems of responsibility, namely the lack of awareness and knowledge of subjects regarding objects. At this point, accountability gains its importance in the concept of reflective responsibility.

\section{RESPONSIBILITY AND ACCOUNTABILITY}

In this section the concept of accountability and its relevance in the area of ICT will be will be defined.

\subsection{Accountability}

Accountability and responsibility are often used synonymously (Johnson, 2001; Weckert \& Adeney, 1997). The etymology suggests that the term has a dual origin, from the Latin accomputare, meaning to compute and the French a conter, to tell a story (Yakel, 2001). The etymology is thus compatible with the "response" of responsibility (Giddens, 1984). Furthermore, the term "account" in "accountability" suggests that people will be taken to account, an accountability can thus refer "to the perception of defending or justifying one's conduct to an audience that has reward or sanction authority, and where rewards or sanctions are perceived to be contingent upon audience evaluation of such conduct" (Beu \& Buckley, 2001)

Here a slightly different definition will be suggested - one that views accountability as one aspect of responsibility. Where responsibility refers to the entire process of ascription of object to subject, accountability is 
concerned with the way in which this relationship can be established and verified. Laudon \& Laudon $(1999,457)$ express this idea in the following way: "Accountability is a feature of systems and social institution: It means that mechanisms are in place to determine who took responsible action, who is responsible." Where "responsibility has to do with tracing the causes of actions and events, of finding out who is answerable in a given situation" (Goodpaster \& Matthews, 1982 p. 133), accountability is the set of mechanisms that allow such tracing of causes, actions, and events. This means that accountability is a necessary but not a sufficient condition of responsibility (Spinello, 1997). Without accountability, that means without the means of attributing the subject to the object, there can be no full process of responsibility ascription. However, even if accountability is unproblematic, responsibility may not be forthcoming because some other aspect of the ascription is not feasible.

The nature of accountability is similar to that of responsibility. It is a social construction. Accountability is easier to handle than responsibility because it concentrates on one aspect of responsibility, namely the link between subject and object. On the other hand, this means that accountability can only be considered when subject and object are defined. For a given subject and object accountability considers the conditions under which they can be linked. It thus has to find solutions or proxies for the problems of responsibility such as lack of knowledge, power, or influence

Let us take a look at our example. A possible set of subject and object might be the $\mathrm{CIO}$ and the cost of the project. In this case, accountability can be simple. It will require the provision of information of project benefits and costs to the CIO in such a way that he or she can influence them. In organizational practice this may turn out to be complicated but theoretically it seems quite straightforward.

Another set of subject and object could be the implementation group and customer privacy. This is more complex, because the subject is a collective and the object is a fuzzy area of ethics and law whose stakeholders are located outside of the organizational boundaries. Accountability would require ways for the implementation group to assess the users' privacy needs and rights. These would have to be fed back into the implementation process. Accountability could thus be constructed with the help of social research tools such as surveys, focus groups user involvement or others. The important thing is that the subject is in such a relationship to the object that the ascription of responsibility is convincing to the stakeholders involved. 
Accountability is of central importance for reflective responsibility. One of the reflective aspects was that of affinity to action. This means that reflective responsibility must ask whether an ascription will lead to action and thus to the desired social change. Responsibility ascriptions to subjects who have no influence or no knowledge of the objects usually cannot make a difference. From the reflective point of view they are therefore useless. Holding the $\mathrm{CIO}$ responsible for data input when she knows nothing about it, is not likely to be successful. Accountability is therefore a central part of every reflective ascription of responsibility. It needs to be considered and made explicit so that the different stakeholders agree on the ascription. If they do not agree, then sanctions are unlikely to fulfil their aims.

\subsection{Accountability and ICT}

There are several possible links between accountability and ICT. A salient one is the use of ICT for the purpose of establishing accountability. ICT is used for establishing accountability where the technology helps identify the relationship between subjects and objects of responsibility. The fundamental idea here is that an essential part of accountability is information and the distribution of information to the relevant stakeholders. Since ICT is designed to capture and disseminate information, it can easily support such processes. In business organizations this can be done by using ICT to mirror movements of money or material.

The detailed inventory tracking systems that ERP systems contain, for example, allow for the ascription of individual pieces to individual persons. Similarly, financial information systems allow for the linking of movements of money to individual actions. These ways of establishing accountability are not new (in fact, they are at least as old as the field of accounting) but they can be greatly helped and improved through ICT use. More generally, one can say that ICT can help track behaviour of all sorts of entities (Skovira, 2003) and thereby allows ascriptions of responsibility.

One can find numerous examples for this sort of accountabilityenhancing use of ICT. In some way most electronically created files can be interpreted in this way. This is true for the above-mentioned business records but it is at least as true in other areas such as health care and related records (Yakel, 2001). Another set of examples is that of public administration and politics.

Political responsibility is a type of responsibility that has not been mentioned here so far. The reason is that it is an exception in many respects. 
For example, it is not necessary to play a causal role in order to be politically responsible. Also, political systems tend to be highly complex, which makes the discursive processes of responsibility ascription difficult and hard to understand. Every government, or at least every democratic government, should be accountable to its citizens. This is one more reason to search for means of creating accountability and ICT can be one. ICT can be used to publish information that allows the citizens to scrutinize the public use of funds and thereby identify good policy and avoid corruption (Barata \& Cain, 2001).

There is thus a good point to be made that ICT can be used for the purposes of accountability. However, at the same time ICT requires new responsibility ascriptions and can become a contentious problems for accountability.

\subsection{Problems of Accountability and ICT}

While ICT can thus be invaluable for providing accountability, it can also have the opposite effect. Nissenbaum (1995) identifies four areas where computers can lead to a dispersion or dissolution of accountability. These are the problem of "many hands", which is created by the fact that computers are complex machines consisting of software and hardware which often renders it practically impossible to establish a link between individuals and functions of a computer (cf. Johnson \& Mulvey, 1995). Part of these problems are software malfunctions or "bugs", which are commonly accepted as inevitable but which again make it difficult to attribute subject and object. A frequent problem is that of the computer as scapegoat, where the technology is used for the express purpose of deflecting accountability and thus responsibility. Finally, Nissenbaum sees a problem in the distribution of property because, on the one hand, ownership rights in intellectual property are asserted strongly but, on the other, no corresponding move to accountability for the property seems to be established. These are issues of the deflection of accountability through ICT that most of us will be familiar with and that should be plausible to most readers.

There tend to be deeper issues of accountability hidden within the makeup of ICT. A fitting example that links nicely with the ERP example I have used throughout the paper is that of accounting information systems. The very name suggests strongly that such systems are meant to establish links of accountability. They link costs to individuals or processes that produce them and thereby establish financial accountability that can be used for the purpose of responsibility ascription. The consequences are often 
manifest. If a unit or a division does not live up to the expected level of profit or other measures then individuals or even the whole unit may be made redundant or outsourced. Similarly, a good fulfilment of financial goals as demonstrated by the accounting system can result in promotions or bonuses. This generally accepted model of accountability through accounting hides the fact that there are a number of value choices on which the whole idea of accounting is based and which, by necessity, have to be coded into the system. This means that the accounting practices, which themselves could be objects of responsibility ascriptions become reified and hidden within the system (Meijer, 2001). This is problematic in the context of our concept of reflective responsibility because it is not open to discursive inquiry. This means that there are accountability practices implicit in ICT which are not subject to accountability.

A related problem is a simplistic understanding of the accountabilityestablishing faculties of ICT. It is often supposed that transparency, here making data or information available, e.g., via the Internet, will lead to accountability. Barat and Cain (2001) discuss this problem with regard to public sector financial accountability. They state that the relationship between accountability and ICT is often oversimplified, which, in turn, may lead to a decrease of accountability rather than an increase.

\section{PATHOLOGIES OF ACCOUNTABILITY}

When writing this paper and thinking about the problems and disadvantages of accountability and ICT, it became increasingly clear to me that there are two fundamentally different disadvantages. One group comprises the above problems where accountability can become problematic because of the use of ICT. Instead of providing structures of accountability, such problems inadvertently have an opposite effect. However, these problems can be overcome by introducing new accountability structures or other measures.

However, there seems to be a different type obstacle to accountability as a supporting mechanism of responsibility, which the present author terms the "pathology of accountability". Such pathologies are given when accountability, despite fulfilling its original purpose, becomes an obstacle to responsibility ascriptions. The point here is that accountability, originally meant to be a support for responsibility ascriptions, becomes independent of the underlying responsibility and produces effects that run counter to the social purpose of responsibility. A fitting example is probably the practice of 
employee surveillance (cf. Stahl et al., 2005). A possible justification of employee surveillance is that it is a measure meant to support or establish accountability within the context of the responsibility ascription that has been agreed on in the work contract. In reality, employee surveillance is often not used as a measure to implement discursive agreement but as a usually one-sided exertion of power. The debate surrounding surveillance suggests that it should itself be viewed as an object of responsibility. This is generally recognized in academia but workplace surveillance is seldom the object of debates in commercial organizations. It has thus turned into a pathological case of accountability through ICT that is reified, changes the original responsibility context and is not open to revision. Instead of supporting responsibility ascription, surveillance as a measure of accountability undermines them.

The final example of such pathological accountability can be our ERP system. One can see the ERP system as an attempt to create accountability. It is meant to collect data from all parts and aspect of the organization which is at least partly used to facilitate responsibility ascriptions. At the same time there is a good probability that the ERP system will be removed from the realm of discourse and function as a tool of power and authority. The underlying responsibility relationships may change over time but reflecting these changes in the system is quite difficulty. Similar to the other examples of pathological accountability, this one also has the potential to fundamentally change the original responsibility ascription without itself being subject to scrutiny. The introduction of a far-reaching system such as an ERP system in a company will usually affect the structure and business processes thereby changing the basis of responsibility ascriptions. These changes will in many cases have moral importance but the ERP system as the cause of change is usually not questioned.

\section{CONCLUSION}

This paper has put forward the argument that responsibility is an important concept to address ethical and moral issues that arise because of the use of ICT. It has discussed the shortcomings of traditional theories of responsibility and suggested the idea of reflective responsibility as a possible solution. Using this as a basis, the concept of accountability was introduced as a supporting structure for reflective responsibility. Accountability was defined as structures and procedures that allow establishing links between responsibility subjects and objects. Without accountability, reflective responsibility is not feasible. In a final step, the influence of ICT on the 
process of constructing accountability was discussed. It turned out that ICT can be used as a support of accountability but that there are also cases where ICT leads to a reduction in accountability.

The most interesting aspect of the problems of ICT and accountability were discussed under the heading of pathologies of accountability. Those are instances where accountability, originally meant to support responsibility, runs counter to the purposes of responsibility and renders the responsibility ascription impossible. The question is what should be done under such circumstances.

One part of the answer to this question will be to return to the nature of responsibility and accountability and keep in mind that both are social constructs. Neither of them is naturally given and both rely on social interaction to become effective. Whenever they become reified, solidified, sedimented, and out of reach of those who are involved, there is good reason to suspect that they need to be reconsidered. This seems to be the main problem of accountability becoming pathological. It happens when the process of establishing a link between a subject and an object is divided from the responsibility context that originally required it. It is then easy for accountability to take on a life of its own and to go counter to the original intention of responsibility. A frequent occurrence of this is the quantification of accountability information. Our ongoing example of the ERP system is based on the idea that accountability information can be quantified. The quantification of accountability is widely spread in modern societies. One can often find an underlying assumption that relevant information is numerical and that responsibility ascription can and should be based on such quantification. It is part of responsibility ascriptions to agree on what constitutes a relevant object and it is thus not problematic if numerical representations of reality are seen as relevant. However, if those representations are translated into accountability systems and if the original meaning of the quantitative data is lost, then we can easily come to the pathological situation where accountability processes require the production of numbers which are not related to the original responsibility context.

How should we react? The general, if possibly not satisfying, answer is that we, as members of collectives that ascribe responsibility and define accountability need to be aware of the ongoing nature of these social constructs. Responsibility ascriptions need to be updated and continued, just like accountability procedures. For large responsibility projects this will be a complex issue. It is nevertheless necessary to keep working on it if we want to avoid the danger of accountability becoming reified and pathological. 
John Stuart Mill famously put forward the argument that truth must remain open to scrutiny and critique, otherwise it will become dogma. I believe that a similar approach should be taken to responsibility. Responsibility ascriptions and the related accountability structures must remain open to discursive challenges, otherwise they run the risk of objectification and thereby of failing to fulfil their purpose or, worse, of having effects that are opposed to the social purpose of responsibility.

\section{REFERENCES}

Barata, K. \& Cain, P. (2001), Information, Not Technology, Is Essential to Accountability: Electronic Records and Public-Sector Financial Management, The Information Society 17, pp. $247-258$

Bayertz, K. (1995), Eine kurze Geschichte der Herkunft der Verantwortung. In: Bayertz, K. (ed.) (1995), Verantwortung: Prinzip oder Problem? Darmstadt, Wissenschaftliche Buchgesellschaft, pp. $3-71$

Beu, D. \& Buckley, M. R. (2001): The Hypothesized Relationship Between Accountability and Ethical Behavior, Journal of Business Ethics 34, pp. $57-73$

Fauconnet, P. (1997), La responsabilité: étude de sociologie, In: Neuberg, Marc (ed.) (1997), La responsabilité - questions philosophiques, Paris, Presses Universitaires de France, pp. $141-152$

Giddens, A. (1984), The Constitution of Society - Outline of the Theory of Structuration, Cambridge: Polity Press

Goodpaster, K. E. \& Matthews, J. B. Jr. (1982), Can a corporation have a moral conscience? Harvard Business Review (Jan - Feb 1982), pp. 132-141

Habermas, J. (1981). Theorie des kommunikativen Handelns - Band I+II. Frankfurt a. M.: Suhrkamp Verlag

Hart, H. L. A. (1948), The Ascription of Responsibility and Rights, Proceedings of the Aristotelian Society 1948: 171 - 194

Johnson, D. G. (2001), Computer Ethics, 3rd edition Upper Saddle River, New Jersey: Prentice Hall

Johnson, D. G. \& Mulvey, J. M. (1995), Accountability and Computer Decision Systems, Communications of the $A C M(38: 12)$, pp. $58-64$

Laudon, K. C. \& Laudon, J. P. (1999), Essentials of Management Information Systems. 4th edition London et al., Prentice Hall

Meijer, A. (2001), Electronic Records Management and Public Accountability: Beyond an Instrumental Approach, The Information Society 17, pp. 259-270

Nietzsche, F. (1987), Argumente gegen Vergeltung und Abschreckung, In: Hoerster, N. (ed.) (1987): Recht und Moral - Texte zur Rechtsphilosophie, Stuttgart, Philip Reclam jun., pp. $229-231$

Nissenbaum, H. (1995), Computing and Accountability, in: Johnson, D. G. \& Nissenbaum, H. (eds.) (1995), Computers, Ethics \& Social Values. Upper Saddle River: Prentice Hall, pp. $526-538$

Skovira, R. J. (2003), The Social Contract Revised: Obligation and Responsibility in the Information Society. In: Azari, R. (ed.) Current Security Management \& Ethical Issues of Information Technology. Hershey et al.: IRM Press, pp. $165-186$ 
Spinello, R. (1997), Case studies in information and computer ethics, Upper Saddle River, $\mathrm{NJ}$ : Prentice Hall

Stahl, B. C. (2004), Responsible Management of Information Systems, Idea Group Publishing, Hershey PA

Stahl, B. C. (2004b), Reflective Responsibility: Using IS to Ascribe Collective Responsibility,: Philosophy of Management (formerly Reason in Practice) (4:1), Special Issue on Organisation and Decision Processes, edited by Leonard Minkes and Tony Gear, pp. $13-24$

Stahl, B. C. (2004), Information, Ethics, and Computers: The Problem of Autonomous Moral Agents,: Minds and Machines 14, Special Issue on the Philosophy of Information, edited by Luciano Floridi, pp. $67-83$

Stahl, B. C.; Prior, M.; Wilford, S. \& Collins, D. (2005), Electronic Monitoring in the Workplace: If People Don't Care, then What is the Relevance? In: Weckert, J. (ed.), Electronic Monitoring in the Workplace: Controversies and Solutions. Idea-Group Publishing, Hershey PA, pp. 50-78

Wallace, R. J. (1996), Responsibility and the Moral Sentiment, Cambridge, Massachusetts / London, England, Harvard University Press

Weckert, J. \& Adeney, D. (1997), Computer and Information Ethics, Westport, Connecticut / London: Greenwood Press

Yakel, E. (2001), The Social Construction of Accountability: Radiologists and Their RecordKeeping Practices, The Information Society 17, pp. 233 - 245 